OPEN ACCESS

International Journal of Environmental Research and

Public Health

ISSN 1660-4601

www.mdpi.com/journal/ijerph

Article

\title{
Association between Fine Particulate Air Pollution and Daily Clinic Visits for Migraine in a Subtropical City: Taipei, Taiwan
}

\section{Chih-Cheng Chen ${ }^{1}$, Shang-Shyue Tsai ${ }^{2}$ and Chun-Yuh Yang ${ }^{3,4, *}$}

1 Department of Pediatrics, Kaohsiung Chang-Gung Memorial Hospital and Chang-Gung University, College of Medicine, Kaohsiung 833, Taiwan; E-Mail: charllysc@hotmail.com

2 Department of Healthcare Administration, I-Shou University, Kaohsiung 824, Taiwan; E-Mail: sionghak@isu.edu.tw

3 Department of Public Health, College of Health Sciences, Kaohsiung Medical University, Kaohsiung 807, Taiwan

4 Division of Environmental Health and Occupational Medicine, National Health Research Institute, Miaoli 350, Taiwan

* Author to whom correspondence should be addressed; E-Mail: chunyuh@kmu.edu.tw; Tel.: +886-7-312-1101 (ext. 2141); Fax: +886-7-311-0811.

Academic Editor: Paul B. Tchounwou

Received: 25 February 2015 / Accepted: 23 April 2015 / Published: 29 April 2015

\begin{abstract}
This study was undertaken to determine whether there was an association between fine particle ( $\left.\mathrm{PM}_{2.5}\right)$ levels and daily clinic visits for migraine in Taipei, Taiwan. Daily clinic visits for migraine and ambient air pollution data for Taipei were obtained for the period from 2006-2011. The odds ratio of clinic visits was estimated using a case-crossover approach, controlling for weather variables, day of the week, seasonality, and long-term time trends. Generally, no significant associations between $\mathrm{PM}_{2.5}$ levels and migraine visits were observed on cool days. On warm days, however, for the single pollutant model (without adjustment for other pollutants), increased clinic visits for migraine were significantly associated with $\mathrm{PM}_{2.5}$ levels, with an interquartile range (IQR) rise associated with a $13 \%(95 \% \mathrm{CI}=8 \%-19 \%)$ elevation in number of migraine visits. In bi-pollutant model, $\mathrm{PM}_{2.5}$ remained significant after the inclusion of sulfur dioxide $\left(\mathrm{SO}_{2}\right)$ or ozone $\left(\mathrm{O}_{3}\right)$ on warm days. This study provides evidence that higher levels of $\mathrm{PM}_{2.5}$ increase the risk of clinic visits for migraine in Taipei, Taiwan.
\end{abstract}


Keywords: fine particulate; air pollution; migraine; case-crossover; clinic visits

\section{Introduction}

Over the past decade, many epidemiologic studies have demonstrated positive associations between ambient levels of airborne particulate matter (PM, generally measured as PM with an aerodynamic diameter $\left.\leq 10 \mu \mathrm{m}\left[\mathrm{PM}_{10}\right]\right)$ and daily mortality [1-5] and hospital admissions or emergency room (ER) visits for cardiovascular and respiratory morbidity [6-8]. The evidence on adverse effects of PM air pollution on public health has led to more stringent standards for levels of PM in outdoor air in the USA and in other countries [9].

While previous studies have primarily used $\mathrm{PM}_{10}$ as an exposure indicator, fine particles (defined as PM with an aerodynamic diameter less than $2.5 \mu \mathrm{m} ; \mathrm{PM}_{2.5}$ ) have become a greater health and regulatory concern due to epidemiologic studies suggesting that $\mathrm{PM}_{2.5}$ might have greater toxicity than larger particles [10-12]. It is now generally accepted that $\mathrm{PM}_{2.5}$ are more harmful to health effect than larger particles $\left(\mathrm{PM}_{10}\right)$ because $\mathrm{PM}_{2.5}$ offer a larger surface area and hence potentially larger concentrations of adsorbed or condensed toxic air pollutants per unit mass [13,14].

Relatively few epidemiologic studies (mainly focused on severe events such as mortality, hospitalizations, and ED visits) have been undertaken which address specifically the health effects of $\mathrm{PM}_{2.5}$, as only a few cities have monitored $\mathrm{PM}_{2.5}$ [15]. Very few have investigated the relationship between $\mathrm{PM}_{2.5}$ levels and general practitioner visits where most patients contact occur but concentrated on respiratory diseases [16-20]; other symptoms have rarely been investigated [21].

Migraine headache is a common clinic problem, an important cause of morbidity in mordern society [22]. Migraines represent an enormous public health concern. In United States, about 18\% of women and $6 \%$ of men report migraines [23], and annual costs attributed to migtaines have been estimated to approximate $\$ 17$ billion [24]. In Taiwan, a population-based survey reported that $14.4 \%$ of women and $4.5 \%$ of men reported suffering from migraine headache [25]. In addition, it was estimated that migraines account for more than 3.7 million lost working days at an estimated lost labor cost of 0.47 billion (Taiwan Dollars) yearly [26].

There are many self-reported triggers for migraines including weather, food, stress, fatigue, menstruation, and infection [27,28]. The association between air pollution or other environmental factors and migraine has not been accepted widely by clinicians [29]. A few studies have suggested that $\mathrm{PM}_{2.5}$ levels may be linked to migraine [30-33]. However, these results require confirmation and also further explorationas using larger datasets.

This study was undertaken to examine the association between $\mathrm{PM}_{2.5}$ levels and clinic visits for migraine among people residing in Taipei city, the biggest metropolitan city of Taiwan, over the six year period from 2006-2011, using a case-crossover design. 


\section{Materials and Methods}

\subsection{Taipei City}

This study examined daily variations in clinic visits for migraine in relation to $\mathrm{PM}_{2.5}$ levels in Taipei for the 6-year period from 2006 through 2011. Taipei is the largest metropolitan city in Taiwan with a population of about 2.64 million and is located in northern Taiwan. The major air pollution source is automobile exhaust emission. Taipei has a subtropical climate, with an annual average temperature of $23{ }^{\circ} \mathrm{C}$ (the months with a mean temperature below $23{ }^{\circ} \mathrm{C}$ are from November through April and May through October are the months with a mean temperature above $23{ }^{\circ} \mathrm{C}$ ).

\subsection{Data Sources and Clinic Visits}

The National Health Insurance (NHI) Program, which provides compulsory universal health insurance, was implemented in Taiwan on 1 March 1995. Under the NHI, 99\% of the island's population receives all forms of health care services including outpatient services, inpatient care, Chinese medicine, dental care, childbirth, physical therapy, preventive health care, home care, and rehabilitation for chronic mental illness. In cooperation with the Bureau of NHI, the National Health Research Institute (NHRI) of Taiwan has created a simple random sample of one million individuals from the entire NHI insured populations for research purposes, which cohort was further validated to be representative of the entire insured population. There were no statistically significant differences in age, gender, and healthcare costs between the sample group and all enrollees, as reported by the NHRI. This dataset (from January 1996 to December 2011) includes all claim data for these $1,000,000$ subjects. These database have previously been used for epidemiological research, and information on prescription use, diagnoses, and hospitalizations has been shown to be of high quality [34,35].

With strict confidentiality guidelines being closely followed in accordance with personal electronic data protection regulations, the NHRI of Taiwan anonymized and maintained the NHI reimbursement data as files suitable for reaearch. In addition, this study was approved by the Ethics Review Board at the Kaohsiung Medical University Hospital (KMUH-IRB-exempt-20130036).

We extracted data on all clinic visits from the medical insurance file for the period 2006-2011. Cases consisted of all patients who had at least one outpatient visit with a primary diagnosis of migraine (International Classification of Diseases, 9th revision [ICD-9] code 346).

\subsection{PM2.5 and Meteorological Data}

Six air quality monitoring stations were established in Taipei city by the Taiwanese Environmental Protection Administration (EPA), a central governmental agency. The monitoring stations were fully automated and routinely monitor levels of five "criteria" pollutants including sulfur dioxide $\left(\mathrm{SO}_{2}\right.$, by ultraviolet fluorescence); particulate matter ( $\mathrm{PM}_{10}$, by beta-ray absorption); nitrogen dioxide $\left(\mathrm{NO}_{2}\right.$, by ultraviolet fluorescence), carbon monoxide ( $\mathrm{CO}$, by nondispersive infrared photometry), and ozone $\left(\mathrm{O}_{3}\right.$, by ultraviolet photometry). However, $\mathrm{PM}_{2.5}$ was not regularly monitored. $\mathrm{PM}_{2.5}$ concentrations in Taiwan

have been measured continuously since 2006. PM 2.5 was measured using tapered element oscillating microbalance method samplers. The availability of the monitoring network for $\mathrm{PM}_{2.5}$ provided an opportunity 
to investigate the impact of $\mathrm{PM}_{2.5}$ on clinic visits for migraine. For each day, hourly air pollution data were obtained for all of the monitoring stations. After calculating the hourly mean of each pollutant from the 6 stations, the 24-h average levels of these pollutants were computed. Daily information on mean temperature and mean humidity was provided by the Taipei Observatory of the Central Weather Bureau.

\subsection{Statistics}

The data were analyzed using the case-crossover design [36,37]. This design is an alternative to Poisson time series regression models for studying the short-term effects attributed to air pollution [38]. In general, the case-crossover design and the time-series approach yielded almost identical results [39-41].

We used the time-stratified approach for the case-crossover analysis [38]. A stratification of time into separate months was made to select referent days as the days falling on the same day of the week within the same month as the index day. Air pollution levels during the case period were compared with exposures occurring on all referent days. This time-stratified referent selection scheme minimizes bias due to nonstationarity of air pollution time-series data [42-44]. The results of previous studies indicated that the increased hospital admissions or clinic visits were associated with high air pollutant levels on the same day or the previous two days [45]. Longer lag times have rarely been described. Thus the cumulative lag up to 2 previous days (i.e., the average air pollution levels of the same and previous 2 days) was used. In the analysis, the adverse health effects of each air pollutant were categorized into one of the two temperature categories: "warm" days (days with a mean temperature above the annual average temperature of the city, i.e., $23^{\circ} \mathrm{C}$ ) and "cool" days (days with a mean temperature below the annual average temperature of the city, i.e., $23^{\circ} \mathrm{C}$ ).

The associations between clinic visits and the levels of $\mathrm{PM}_{2.5}$ were estimated using the odds ratio (OR) and their $95 \%$ confidence intervals (CI) which were produced using conditional logistic regression (PROC PHREG in SAS software) with weights equal to the number of clinic visits on that day. All statistical analyses were performed using the SAS package (version 9.1; SAS Institute, Inc., Cary, NC, USA). Both single-pollutant models and multi-pollutant models were fitted with a different combination of pollutants (up to two pollutants per model) to assess the stability of the effect of PM2.5. Exposure levels to air pollutants were entered into the models as continuous variables. Meteorologic variables (daily average temperature and humidity on the same day) which might play a confounding role were included in the model. In all analyses, we modeled the mean temperature at lag 0 as a quadratic function, mean humidity at lag 0 , and pollutants as a linear function of the 3 -day moving average of current and previous 2 days concentrations (lag $0-2$ ). Inclusion of barometric pressure did not change the effect estimates and therefore it was not considered in the final model. ORs were calculated for the interquartile difference (between the 25th and the 75th percentile) of each pollutant, as observed during the study period. To examine potential effect modification of the effect of temperature on the risk of clinic visits for migraine, we conducted analyses stratified by the cool or warm days as described above. We calculated Chi-squre statistic and corresponding two-sided p-values to assess the heterogeneity of the temperature regression coefficients from the two strata. 


\section{Results and Discussion}

During the six years of the study, there were a total of 13,676 migraine clinic visits in Taipei city. The descriptive statistics for clinic visits and corresponding environmental data are shown in Table 1. The average levels of $\mathrm{PM}_{2.5}$ during the study period was $29.74 \mu \mathrm{g} / \mathrm{m}^{3}$ (there were 1226 days (56\%) when the levels of $\mathrm{PM}_{2.5}$ were above the WHO threshold). There was an average of 6.24 daily migraine visits in the city over the study period.

Table 1. Distribution of daily clinic visits, weather, and air pollution variables in Taipei, Taiwan, 2006-2011.

\begin{tabular}{ccccccc}
\hline \multirow{2}{*}{ Variable $^{\text {a }}$} & \multirow{2}{*}{ Min } & \multicolumn{3}{c}{ Percentile } & \multirow{2}{*}{ Max } & Mean \\
\cline { 3 - 5 } & & $\mathbf{2 5 \%}$ & $\mathbf{5 0 \%}$ & $\mathbf{7 5 \%}$ & & \\
\hline $\mathrm{PM}_{10}\left(\mu \mathrm{g} / \mathrm{m}^{3}\right)$ & 14.26 & 34.23 & 45.79 & 61.04 & 888.02 & 50.67 \\
$\mathrm{PM}_{2.5}\left(\mu \mathrm{g} / \mathrm{m}^{3}\right)$ & 8.35 & 19.28 & 26.93 & 36.76 & 140.54 & 29.74 \\
$\mathrm{SO}_{2}(\mathrm{ppb})$ & 1.00 & 2.58 & 3.51 & 4.72 & 11.14 & 3.79 \\
$\mathrm{NO}_{2}(\mathrm{ppb})$ & 3.22 & 19.86 & 23.65 & 28.35 & 61.94 & 24.44 \\
$\mathrm{CO}(\mathrm{ppm})$ & 0.13 & 0.49 & 0.62 & 0.78 & 1.99 & 0.66 \\
$\mathrm{O}_{3}(\mathrm{ppb})$ & 4.00 & 17.92 & 23.77 & 30.42 & 70.89 & 24.67 \\
Temperature $\left({ }^{\circ} \mathrm{C}\right)$ & 9.05 & 19.33 & 24.07 & 28.49 & 33.18 & 23.60 \\
Humidity $(\%)$ & 23.56 & 66.68 & 73.13 & 79.70 & 94.19 & 72.86 \\
Migraine visits & 0 & 3 & 6 & 9 & 24 & 6.24 \\
\hline
\end{tabular}

Abbreviation: Min, minimum value; Max, maximum value; ${ }^{\text {a }} 24$-h average.

The Pearson's correlation coefficients among the air pollutants are presented in Table 2. Table 3 shows the effect estimates of $\mathrm{PM}_{2.5}$ on clinic visits for migraine in single-pollutant models and bi-pollutant models. We found evidence that the relationship between $\mathrm{PM}_{2.5}$ levels and migraine visits differed by season. Generally, no significant associations between $\mathrm{PM}_{2.5}$ levels and migraine visits were observed on cool days.

On warm days, for the single pollutant model (without adjustment for other pollutants), increased clinic visits for migraine were significantly associated with $\mathrm{PM}_{2.5}$ levels, with an IQR rise associated with a $13 \%(95 \% \mathrm{CI}=8 \%-19 \%)$ elevation in number of migraine visits. In bi-pollutant model, $\mathrm{PM}_{2.5}$ remained significant after the inclusion of $\mathrm{SO}_{2}$ or $\mathrm{O}_{3}$ on warm days.

Table 2. Correlation coefficients among air pollutants.

\begin{tabular}{ccccccc}
\hline Variable & $\mathbf{P M}_{\mathbf{1 0}}$ & $\mathbf{P M}_{\mathbf{2 . 5}}$ & $\mathbf{S O}_{\mathbf{2}}$ & $\mathbf{N O}_{\mathbf{2}}$ & $\mathbf{C O}$ & $\mathbf{O}_{\mathbf{3}}$ \\
\hline $\mathrm{PM}_{10}$ & 1.00 & 0.79 & 0.46 & 0.37 & 0.37 & 0.29 \\
$\mathrm{PM}_{2.5}$ & - & 1.00 & 0.60 & 0.55 & 0.54 & 0.32 \\
$\mathrm{SO}_{2}$ & - & - & 1.00 & 0.52 & 0.51 & 0.07 \\
$\mathrm{NO}_{2}$ & - & - & - & 1.00 & 0.89 & -0.06 \\
$\mathrm{CO}$ & - & - & - & - & 1.00 & -0.22 \\
$\mathrm{O}_{3}$ & - & - & - & - & - & 1.00 \\
\hline
\end{tabular}

This study is one of the few that investigated the association between exposure to $\mathrm{PM}_{2.5}$ and clinic visits for migraine and is the first in Asia. We chose to study Taipei because it is a large city with adequate numbers of outpatient visits, and extensive air pollution data are available and our results should be 
applicable to other cities with similar emission sources. Data demonstrated that the levels of $\mathrm{PM}_{2.5}$ were positively associated with increases in the daily visits for migraine after inclusion of $\mathrm{SO}_{2}$ or $\mathrm{O}_{3}$ on warm days. The observed effects of $\mathrm{PM}_{2.5}$ were not maintained in the presence of $\mathrm{NO}_{2}$ or $\mathrm{CO}$. This might be due to the collinearity between $\mathrm{PM}_{2.5}$ levels and concentrations of $\mathrm{NO}_{2}$ or $\mathrm{CO}$ levels, which is a common problem in this type of study.

Table 3. Association between $\mathrm{PM}_{2.5}$ exposure and clinic visits for migraine in Taipei, Taiwan, 2006-2011.

\begin{tabular}{|c|c|c|}
\hline Temperature & \multicolumn{2}{|c|}{$\mathrm{PM}_{2.5}$ OR $(95 \% \mathrm{CI})^{\mathrm{a}}$} \\
\hline \multirow{5}{*}{$\geq 23^{\circ} \mathrm{C}(1222$ days $)$} & Without adjustment $^{\mathrm{b}}$ & $1.13(1.08-1.19)$ \\
\hline & Adjusted for $\mathrm{SO}_{2}{ }^{\mathrm{c}}$ & $1.15(1.09-1.22)$ \\
\hline & Adjusted for $\mathrm{NO}_{2}{ }^{\mathrm{c}}$ & $1.03(0.97-1.10)$ \\
\hline & Adjusted for $\mathrm{CO}^{\mathrm{c}}$ & $1.03(0.97-1.09)$ \\
\hline & Adjusted for $\mathrm{O}_{3}{ }^{\mathrm{c}}$ & $1.13(1.07-1.20)$ \\
\hline \multirow{5}{*}{$<23{ }^{\circ} \mathrm{C}$ (969 days) } & Without adjustment $^{\mathrm{b}}$ & $1.02(0.98-1.07)$ \\
\hline & Adjusted for $\mathrm{SO}_{2}{ }^{\mathrm{c}}$ & $1.13(1.06-1.20)$ \\
\hline & Adjusted for $\mathrm{NO}_{2}{ }^{\mathrm{c}}$ & $0.97(0.92-1.02)$ \\
\hline & Adjusted for $\mathrm{CO}^{\mathrm{c}}$ & $1.02(0.96-1.08)$ \\
\hline & Adjusted for $\mathrm{O}_{3}{ }^{\mathrm{c}}$ & $1.03(0.98-1.08)$ \\
\hline
\end{tabular}

Studies on the effect of $\mathrm{PM}_{2.5}$ on migraine visits are rare, and results have been inconsistent. Dales et al. [32] conducted a study in seven urban centers in Chile, and found no evidence of an association between migraine hospitalization and exposure to $\mathrm{PM}_{2.5}$. A study in Boston by Mukamal et al. [33] reported no significant association between $\mathrm{PM}_{2.5}$ and ER visits for migraine. In contrast, Szyszkowicz et al. [30] reported an association of $4.6 \%(95 \% \mathrm{CI}=1.2 \%-8.1 \%)$ increase in risk of daily ER migraine visits for PM 2.5 mean level change of $8.3 \mu \mathrm{g} / \mathrm{m}^{3}$. A study in Edmonton, Canada, by Szyszkowicz et al. [31] reported an IQR $\left(6.2 \mu \mathrm{g} / \mathrm{m}^{3}\right)$ increment in the level of PM2.5 was associated with a $3.3 \%(95 \% \mathrm{CI}=0.6 \%-6.0 \%)$ rise in daily ER visits for migraine. In this study, a $7.44 \%$ (which corresponds to $13 \%$ increase per IQR increment) rise in daily clinic visits for migraine per $10 \mu \mathrm{g} / \mathrm{m}^{3}$ increment was found in the three day moving average (lag 2) concentrations of $\mathrm{PM}_{2.5}$ for warm days.

Because pollutants can vary considerably by season, especially $\mathrm{O}_{3}$ and particles, and therefore seasonal interactions between air pollutants and hospital admissions or clinic visits have often been reported. However, previous studies were conducted mostly in countries where the climates are substantially different from that in Taipei [46,47], which has a subtropical climate with no apparent 4-season cycle. Hence in this study the possible interaction of seasonality on the effects of air pollutants was not considered; but temperature was used instead. In our study, effects were observed only on warm days (effect modification). It was possible to confirm that PM effects varied by season [33]. The observed seasonal variation in effect estimates might be attributed to variation in exposure patterns. Individuals in Taipei are more likely to go outdoors and open the windows in the warm season than in cool season (higher exposure); thus, monitored $\mathrm{PM}_{2.5}$ concentrations may be closer to personal exposure to $\mathrm{PM}_{2.5}$ in the warm than cool season (better exposure assessment) [48]. This condition may attenuate the 
PM2.5-induced effects in the cool season. Furthermore, our study demonstrated greater effect estimates per unit increase of $\mathrm{PM}_{2.5}$ than previous reports. Variations in seasonal and regional effect estimates may in part result from differences in the chemical composition of $\mathrm{PM}_{2.5}$ [49]. Differences in population characteristics or PM sources, composition, absolute levels, or daily variability likely also contribute to the heterogeneity observed across studies. Of note, $\mathrm{PM}_{2.5}$ levels in this study were higher than those noted in previous studies. Nevertheless, the seasonal pattern of air pollution health effects need to be further investigated.

Air pollution has consistently been associated with increased hospital admissions or ER visits in cities throughout the world [50]. Recent studies suggest that the increase is due primarily to $\mathrm{PM}_{2.5}$ [11,51]. Major $\mathrm{PM}_{2.5}$ components vary by region and by season, but typically include ammonium sulfate and nitrate, elemental carbon, carbonaceous species, carbonates, metals, and water [51,52]. Despite considerable research, the relative toxicity of different constituents of $\mathrm{PM}_{2.5}$ remains unclear but likely varies [51].

An association between $\mathrm{PM}_{2.5}$ and migraine headache is biological plausible. Some pathophysiological hypotheses may be inferred to explain the association between the short-term effects of $\mathrm{PM}_{2.5}$ and migraine visits. $\mathrm{PM}_{2.5}$ have been postulated as the effective toxic fraction of $\mathrm{PM}$, because they promote and maintain oxidative stress both at the respiratory level (the entry system) and at the systemic level where oxidative stress induces inflammatory reactions [53]. Cardiovascular effects may reflect neurogenic and inflammatory processes [54]. Neurogenic switching, in which exposure to irritants produces an afferent signal that triggers a distant response, potentially in a different organ system, has been hypothesized as a mechanism through which neurogenic inflammation triggered by air pollution exposures may cause migraine headache $[55,56]$. Alternatively, air pollutants may impair endothelial-dependent vasodialation leading to the development of migraine headaches [57]. Given the marked effects of $\mathrm{PM}_{2.5}$ observed in previous studies of cardiovascular disease, the role of these particles as a trigger of migraine headache clearly merits additional study [33].

The origin of chemical pollutants in an urban atmosphere is known to be principally due to road traffic [58]. $\mathrm{PM}_{2.5}$ concentrations have a less important natural component than $\mathrm{PM}_{10}$ concentrations. This smaller natural component makes $\mathrm{PM}_{2.5}$ a more reliable indicator than $\mathrm{PM}_{10}$ for measuring anthropic activity in a large city [59].

The case-crossover study design was proposed by Maclure [36] to study the effects of transient, intermittent exposures on the subsequent risk of rare acute-onset events in close temporal proximity to exposure. This design offers the ability to control many confounders by design rather than by statistical modelling. This design is an adaptation of the case-control study in which each case serves as his or her own referent. Therefore time-invariant subject-specific variables such as gender, age, underlying chronic disease, or other individual-level characteristics do not act as confounders. In addition, time-stratified approach [38] was found to be effective in controlling for seasonality, time trends, and chronic and slowly varying potential confounders [42-44]. In general, the case-crossover design and the general additive model (GAM) approach, which has been the analytic method of choice for studying the short-term adverse effects of air pollution since 1990 [60], produced almost identical results [39-41].

For a factor to confound the relationship between $\mathrm{PM}_{2.5}$ levels and clinic visits for migraine it needs to be correlated with both variables. It is unlikely that smoking and other indoor pollutants confound the present association since day to day variations in indoor emissions, including smoking need not be correlated with outdoor air pollution. 
Exposure measurement error is a common concern in environmental epidemiology. Air pollutant levels were assigned from fixed, outdoor monitoring stations to individuals to estimate exposure. A common assumption is that the spatial distributions of certain pollutants, especially smaller particulate matter, are homogeneously distributed within large urban areas and that the concentrations between sites are well correlated. However, recent studies suggest that there may be greater variation within urban areas than previously reported $[61,62]$. Hence, exposure measurement errors resulting from the differences between the population-average exposure and ambient $\mathrm{PM}_{2.5}$ levels are not avoidable. However, the potential for misclassification of exposure due to the lack of personal measurements of fine PM exposure in this study is of the Berkson type and is known to cause a bias toward the null and an underestimate of the association $[45,63]$. Nonetheless, caution is advised when using central monitoring sites as proxies for population exposure in epidemiological studies without a prior analysis of spatial uniformity [61].

Our study population is homogenous in terms of race compared with populations in other cities. This study was conducted in a subtropical city. These facts may restrict somewhat the generalizability of these findings to other locations with different meteorological and racial characteristics. Furthermore, behavior such as air conditioning use or time spent outdoors may affect personal exposures. This might affect the magnitude of the observed associations in comparison with other geographic locations.

\section{Conclusions}

In summary, this study provides evidence of associations between short-term exposure to $\mathrm{PM}_{2.5}$ and clinic visits for migraine. The ecological design of the study precludes the inference of cause and effect. However, these findings reinforce the possible role of $\mathrm{PM}_{2.5}$ on clinic visits for migraine.

\section{Acknowledgments}

This study is based in part on data from the National Insurance Research Database provided by the Bureau of National Health Insurance, Department of Health and managed by National Health Research Institutes. The interpretation and conclusions contained herein do not represent those of Bureau of National Health Insurance, Department of Health or National Health Research Institutes. This study was supported by a grant from National Science Council, Executive Yuan, Taiwan (NSC 102-2314-B-037-065-MY2).

\section{Author Contributions}

Chih-Cheng Chen wrote the manuscript. Shang-Shyue Tsai did the statistical analysis. Chun-Yuh Yang contributed to study design and interpretation of the data.

\section{Conflicts of Interest}

The authors declare no conflict of interest. 


\section{References}

1. Pope, C.A.; Burnett, R.T.; Thurston, G.D.; Thun, M.J.; Calle, E.E.; Krewski, D.P.; Godleski, J.J. Cardiovascular mortality and long-term exposure to particulate air pollution: Epidemiological evidence of general pathophysiological pathways of disease. Circulation 2004, 109, 71-77.

2. Qian, Y.; Zhu, M.; Cai, B.; Yang, Q.; Kan. H.; Song, G.; Jin, W.; Han, M.; Wang, C. Epidemiologic evidence on association between ambient air pollution and stroke mortality. J. Epidemiol. Community Health 2013, 67, 635-640.

3. Shang, Y.; Sun, Z.; Cao, J.; Wang, X.; Zhong, L.; Bi, X.; Li, H.; Liu, W.; Zhu, T.; Huang, W. Systematic review of Chinese studies of short-term exposure to air pollution and daily mortality. Environ. Int. 2013, 54, 100-111.

4. Yorifuji, T.; Kashima, S. Association of particulate matter with stroke mortality: A muticity in Japan. J. Occup. Environ. Med. 2013, 55, 768-771.

5. WHO. WHO Air Quality Guidelines. Global Update 2005; World Health Organization: Geneva, Switzerland, 2006.

6. Samet, J.; Krewski, D. Health effects associated with exposure to ambient air pollution. J. Toxicol. Environ. Health A 2007, 70, 227-242.

7. Atkinson, R.W.; Kang, S.; Anderson, H.R.; Mills, I.C.; Walton, H.A. Epidemiologic time series studies of $\mathrm{PM}_{2.5}$ and daily mortality and hospital admissions: A systematic review and meta-analysis. Thorax 2014, 69, 660-665.

8. Basagana, X.; Jacquemin, B.; Karanasiou, A.; Ostro, B.; Querol, X.; Agis, D.; Alessandrini, E.; Alguacil, J.; Artinano, B.; Catrambone, M.; et al. Short-term effects of particulate matter constituents on daily hospitalizations and mortality in five South-European cities: Results from the MED-PARTICLES project. Environ. Int. 2015, 75, 151-158.

9. Dominici, F.; Peng, R.D.; Bell, M.L.; Pham, L.; McDermott, A.; Zeger, S.L.; Samet, J.M. Fine particulate air pollution and hospital admission for cardiovascular and respiratory diseases. J. Am. Med. Assoc. 2006, 295, 1127-1134.

10. Cifuentes, L.A.; Vega, J.; Kopfer, K.; Lave, L.B. Effect of the fine fraction of particulate matter versus the coarse mass and other pollutants on daily mortality in Santiago Chile. J. Air Waste Manage. Assoc. 2000, 50, 1287-1298.

11. Schwartz, J.; Dockery, D.W.; Neas, L.M. Is daily mortality associated specifically with fine particles? J. Air Waste Manag. Assoc. 1996, 46, 927-939.

12. Zanobetti, A.; Franklin, M.; Koutrakis, P.; Schwartz, J. Fine particulate air pollution and its components in association with cause-specific emergency admissions. Environ. Health 2009, 8, doi:10.1186/1476-069X-8-58.

13. Wilson, W.E.; Suh, H.H. Fine particles and coarse particles: Concentration relationship relevant to epidemiologic studies. J. Air Waste Manag. Assoc. 1997, 47, 1238-1249.

14. Pope, C.A.; Dockery, D.W. Health effects of fine particulate air pollution: Lines that connect. J. Air Waste Manag. Assoc. 2006, 36, 709-742.

15. Host, S.; Larrieu, S.; Pascal, L.; Blanchard, M.; Declercq, C.; Fabre, P.; Jusot, J.F.; Chardon, B.; le Tertre, A.; Wagner, V.; et al. Short-term associations between fine and coarse particles and hospital admissions for cardiorespiratory diseases in six French cities. Occup. Environ. Med. 2008, 65, 544-551. 
16. Chardon, B.; Lefrance, A.; Granados, D.; Gremy, I. Air pollution and doctor's house calls for respiratory diseases in the Greater Paris area (2000-2003). Occup. Environ. Med. 2007, 64, $320-324$.

17. Hajat, S.; Haines, A.; Goubet, S.A.; Atkinson, R.W.; Anderson, H.R. Association of air pollution with daily GP consultations for asthma and other lower respiratory conditions in London. Thorax 1999, 54, 597-605.

18. Hajat, S.; Haines, A.; Atkinson, R.W.; Bremner, S.A.; Anderson, H.R., Emberlin, J. Association between air pollution and daily consultations with general practitioners for allergic rhinitis in London, United Kingdom. Am. J. Epidemiol. 2001, 153, 704-714.

19. Hajat, S.; Anderson, H.R.; Atkinson, R.W.; Haines, A. Effects of air pollution on general practitioner consultations for upper respiratory diseases in London. Occup. Environ. Med. 2002, 59, 294-299.

20. Wong, T.W.; Tam, W.; Tak, S.Y.; Wun, Y.T.; Wong, A.H.; Wong, C.M. Association between air pollution and general practitioner visit for respiratory diseases in Hong Kong. Thorax 2006, 61, $585-591$.

21. Larrieu, S.; Lefranc, A.; Gault, G.; Chatignoux, E.; Couvy, F.; Jouves, B.; Filleul, L. Are the short-term effects of air pollution restricted to cardiorespiratory diseases? Am. J. Epidemiol. 2009, 169, 1201-1208.

22. Stovner, L.J.; Hagen, K.; Jensen, R.; Katsarava, Z.; Scher, A.; Steiner, T.; Zwart, J.A. The global burden of headache: A documentation of headache prevalence and disability worldwide. Cephalalgia 2007, 27, 193-210.

23. Lipton, R.B.; Stewart, W.F.; Diamond, S.; Diamond, M.L.; Reed, M. Prevalence and burden of migraine in the United States: Data from the American Migraine Study II. Headache 2001, 41, 646-657.

24. Goldberg, L.D. The cost of migraine and its treatment. Am. J. Manag. Care 2005, 11, S62-S67.

25. Wang, S.J.; Fuh, J.L.; Young, Y.H.; Lu, S.R.; Shia, B.C. Prevalence of migraine in Taipei, Taiwan: A population-based survey. Cephalalgia 2000, 20, 566-572.

26. Fuh, J.L.; Wang, S.J.; Lu, S.R. Impact of migraine on the employed labor force in Taiwan. J. Chin. Med. Assoc. 2008, 71, 74-78.

27. Prince, P.B.; Rapaort, A.M.; Sheftell, F.D.; Tepper, S.J.; Bigal, M.E. The effect of weather on headache. Headache 2004, 44, 596-602.

28. Chabriat, H.; Danchot, J.; Michel, P.; Joire, J.E.; Henry, P. Precipitating factors of headaches. A perspective study in a national control-matched survey in migraineurs and non-migraineurs. Headache 1999, 39, 335-338.

29. Frideman, D.I.; de Ver Dye, T. Migraine and environment. Headache 2009, 49, 941-952.

30. Szyszkowicz, M.; Kaplan, G.G.; Grafstein, E.; Rowe, B.H. Emergency department visits for migraine and headache: A multi-city study. Int. J. Occup. Environ. Health 2009, 22, 235-242.

31. Szyszkowicz, M.; Stieb, D.M.; Rowe, B.H. Air pollution and daily ED visits for migraine and headache in Edmonton, Canada. Am. J. Emerg. Med. 2009, 27, 391-396.

32. Dales, R.E.; Cakmak, S.; Vidal, C.B. Air pollution and hospitalization for headache in Chile. Am. J. Epidemiol. 2009, 170, 1057-1066.

33. Mukamal, K.J.; Wellenius, G.A.; Suh, H.H.; Mittleman, M.A. Weather and air pollution as triggers of severe headaches. Neurology 2009, 72, 922-927. 
34. Chiu, H.F.; Ho, S.C.; Chang, C.C.; Wu, T.N.; Yang, C.Y. Statins are associated with a reduced risk of gastric cancer: A population-based case-control study. Am. J. Gastroenterol. 2011, 106, 2098-2103.

35. Cheng, M.H.; Chiu, H.F.; Ho, S.C.; Yang, C.Y. Statin use and the risk of female lung cancer: A population-based case-control study. Lung Cancer 2012, 75, 275-279.

36. Maclure, M. The case-crossover design: A method for studying transient effects on the risk of acute events. Am. J. Epidemiol. 1991, 133, 144-153.

37. Mittleman, M.A.; Maclure, M.; Robins, J.M. Control sampling strategies for case-crossover studies: An assessment of relative efficiency. Am. J. Epidemiol. 1995, 142, 91-98.

38. Levy, D.; Lumley, T.; Sheppard, L.; Kaufman, J.; Checkoway, H. Referent selection in case-crossover analyses of acute health effects of air pollution. Epidemiology 2001, 12, 186-192.

39. Neas, L.N.; Schwartz, J.; Dockery, D. A case-crossover analysis of air pollution and mortality in Philadelphia. Environ. Health Perspect. 1999, 107, 629-631.

40. Lee, J.T.; Schwartz, J. Reanalysis of the effects of air pollution on daily mortality in Seoul, Korea: A case-crossover design. Environ. Health Perspect. 1999, 107, 633-636.

41. Lu, Y.; Zeger, S. On the equivalence of case-crossover and time series methods in environmental epidemiology. Biostatistics 2007, 8, 337-344.

42. Lumley, T.; Levy, D. Bias in the case-crossover design: Implications for studies of air pollution. Environmetrics 2000, 11, 689-704.

43. Janes, H.; Sheppard, L.; Lumley, T. Case-crossover analyses of air pollution exposure data: Referent selection strategies and their implications for bias. Epidemiology 2005, 16, 717-726.

44. Mittleman, M.A. Optimal referent selection strategies in case-crossover studies: A settled issue. Epidemiology 2005, 16, 15-16.

45. Katsouyanni, K.; Touloumi, G.; Spix, C.; Schwartz, J.; Balducci, F.; Medina, S.; Rossi, G.; Wojtyniak, B.; Sunyer, J.; Bacharova, L.; et al. Short term effects of ambient sulphur dioxide and particulate matter on mortality in 12 European cities: Results from time series data from the APHEA project. Br. Med. J. 1997, 314, 1658-1663.

46. Chiu, H.F.; Tsai, S.S.; Weng, H.H.; Yang, C.Y. Short-term effects of fine particulate air pollution on emergency room visits for cardiac arrhythmias: A case-crossover study in Taipei. J. Toxicol. Environ. Health A 2013, 76, 614-623.

47. Chang, C.C.; Kuo, C.C.; Liou, S.H.; Yang, C.Y. Fine particulate air pollution and hospital admissions for myocardial infarction in a subtropical city: Taipei, Taiwan. J. Toxicol. Environ. Health A 2013, $76,440-448$.

48. Tsai, S.S.; Chang, C.C.; Yang, C.Y. Fine particulate air pollution and hospital admissions for chronic obstructive pulmonary disease: A case-crossover study in Taipei. Int. J. Environ. Res. Public Health 2013, 10, 6015-6026.

49. Bell, M.L.; Ebisu, K.; Peng, R.D.; Walker, J.; Samet, J.M.; Zeger, S.L.; Dominici, F. Seasonal and regional short-term effects of fine particles on hospital admissions in 202 US counties, 1999-2005. Am. J. Epidemiol. 2008, 168, 1301-1310.

50. Bedeschi, E.; Campari, C.; Candela, S.; Collini, G.; Caranci, N.; Frasca, G.; Galassi, C.; Francesca, G.; Vigotti, M.A. Urban air pollution and respiratory emergency visits at pediatric unit, Reggio Emilia, Italy. J. Toxicol. Environ. Health A 2007, 70, 261-265. 
51. Suh, H.H.; Zanobetti, A.; Schwartz, J.; Coull, B.A. Chemical properties of air pollutants and cause-specific hospital admissions among the elderly in Atlanta, Georgia. Environ. Health Perspect. 2011, 119, 1421-1428.

52. Peng, R.D.; Bell, M.L.; Geyh, A.S.; McDermott, A.; Zeger, S.L.; Samet, J.M.; Dominici, F. Emergency admissions for cardiovascular and respiratory diseases and the chemical composition of fine particle air pollution. Environ. Health Perspect. 2009, 117, 957-963.

53. MacNee, W.; Donaldson, K. Mechanisms of lung injury caused by $\mathrm{PM}_{10}$ and ultrafine particles with special references to COPD. Eur. Respir. J. 2003, 21 (Suppl. 40), 47s-51s.

54. Brook, R.D.; Franklin, B.; Cascio, W.; Hong, Y.; Howard, G.; Lipsett, M.; Luepker, R.; Mittleman, M.; Samet, J.; Smith, S.C.; et al. Air pollution and cardiovascular disease. A statement for healthcare professionals from the Expert Panel on Population and Prevention Science of the American Heart Association. Circulation 2004, 109, 2655-2671.

55. Meggs, W.J. Neurogenic inflammation and sensitivity to environmental chemicals. Environ. Health Perspect. 1993, 101, 234-238.

56. Meggs, W.J. Neurogenic switching: A hypothesis for mechanism for shifting the site of inflammation in allergy and chemical sensitivity. Environ. Health Perspect. 1995, 103, 54-56.

57. Tornqvist, H.; Mills, N.L.; Gonzalez, M.; Miller, M.R.; Robinson, S.D.; Megson, I.L.; Macnee, W.; Donaldson, K.; Soderberg, S.; Newby, D.E.; et al. Persistent endothelial dysfunction in humans after diesel exhaust inhalation. Am. J. Respir. Crit. Care Med. 2007, 176, 395-400.

58. Linares, C.; Diaz, J. Short-term effect of concentrations of fine particulate matter on hospital admissions due to cardiovascular and respiratory causes among the over-75 age group in Madrid, Spain. Public Health 2010, 124, 28-36.

59. Linares, C.; Diaz, J. Short-term effect of $\mathrm{PM}_{2.5}$ on daily hospital admissions in Madrid (2003-2005). Int. J. Environ. Health Res. 2010, 20, 129-140.

60. Schwartz, J.; Marcus, A. Mortality and air pollution in London: A time series analysis. Am. J. Epidemiol. 1990, 131, 185-194.

61. Wilson, J.G.; Kingham, S.; Pearce, J.; Sturman, A.P. A review of intraurban variations in particulate air pollution: Implications for epidemiological research. Atmos. Environ. 2005, 39, 6444-6462.

62. Mangia, C.; Gianicolo, E.A.; Bruni, A.; Vigotti, M.A.; Cervino, M. Spatial variability of air pollutants in the city of Taranto, Italy and its potential impact on exposure assessment. Environ. Monit. Assess. 2013, 185, 1719-1735.

63. Zeger, S.L.; Thomas, D.; Dominici, F.; Samet, J.M.; Schwartz, J.; Dockery, D.; Cohen, A. Exposure measurement error in time-series studies of air pollution: Concepts and consequences. Environ. Health Perspect. 2000, 108, 419-426.

(C) 2015 by the authors; licensee MDPI, Basel, Switzerland. This article is an open access article distributed under the terms and conditions of the Creative Commons Attribution license (http://creativecommons.org/licenses/by/4.0/). 